УДК 378.026

DOI:

Ірина Шалімова, кандидат педагогічних наук, дочент кафедри педагогіки, методики та менеджментуосвіти Украӥнської інженерно-педагогічної академії

Валентина Бурбига, кандидат педагогічних наук, доиент кафедри педагогіки, методики та менеджменту освіти Української інженерно-педагогічної академії

\title{
МОДЕЛЬ ФОРМУВАННЯ ДИДАКТИЧНОЇ КУЛЬТУРИ ВИКЛАДАЧА ВНЗ
}

У статті здійснено теоретичне дослідження та подано визначення дидактичної культури викладача як суспільно-педагогічного феномена і важливої складової професійно-педагогічної культури, досліджено ї̈ генезис; розроблено модель формування дидактичної культури викладача ВНЗ, яка враховує основні тенденції сучасної парадигми освіти та специфіку навчального закладу; викладено матеріали експериментального впровадження запропонованої моделі та підтверджено інтерпретачію дидактичної культури викладача як одного з факторів успішності його професійної діяльності.

Ключові слова: професійно-педагогічна культура; дидактична культура; інновачійне середовище; викладач ВНЗ. Рис. 2. Табл. 1. Літ. 9.

\author{
Iryna Shalimova, Ph.D.(Pedagogy), Associate Professor of the Pedagogy, \\ Methods and Management of Education Department \\ Ukrainian Engineering and Pedagogical Academy \\ Valentyna Burbyha, Ph.D.(Pedagogy), Associate Professor of the Pedagogy, \\ Methods and Management of Education Department \\ Ukrainian Engineering and Pedagogical Academy
}

\section{A MODEL OF FORMATION OF DIDACTIC CULTURE OF THE TEACHER OF HIGHER EDUCATION ESTABLISHMENT}

The article deals with theoretical research and describes the definition of the didactic culture of the teacher of higher educational institution as a social and pedagogical phenomenon and an important component of vocational and pedagogical culture, and investigates its genesis.

In the structure of didactic culture, the motivational-value, innovation-technological and individual-creative structural components are allocated. The criteria of the formation of the didactic culture of a teacher of a higher educational institution are proposed: technological readiness; readiness for implementation of innovative didactic activity; an innovative orientation of didactic activity; a degree of development of pedagogical thinking; the desire for professional and pedagogical self-improvement; the degree of creative self-realization. Four levels of the formation of didactic culture are defined: adaptive, reproductive, heuristic, and creative ones. The method of theoretical comprehension of the problem of the formation and development of the didactic culture of a teacher of a higher educational establishment in the study became a modeling, which is a universal way of knowing reality and is widespread in pedagogical science.

The model of the formation of the teacher's teaching didactic culture, which takes into account the main tendencies of the modern paradigm of education and the specifics of the educational institution, is developed. In the proposed model, the process of forming didactic culture is represented by nine functional blocks containing information focused on the formation of a certain group of professionally and personally significant qualities: 1) a systematic vision of pedagogical reality; 2) the ability to integrate with the pedagogical experience of others; 3) an analytical and forecast activity, modeling; 4) the formation of the subject area; 5) possession of pedagogical technologies; 6) the formation of pedagogical reflection; 7) the formation of individual humanistic orientation; 8) the formation of creative qualities of the personality of the teacher; 9) the formation of reflexive culture.

The article outlines the experimental implementation of the proposed model and verifies the interpretation of the teacher's teaching culture as a factor in the success of his professional activities.

Keywords: professional-pedagogical culture; didactic culture; an innovative environment; a teacher of higher educational institutions.

П остановка проблеми. Глибокі соціальні й економічні зрушення, що відбуваються у третьому тисячолітті в Україні, спонукають до реформування системи освіти, яка має сприяти утвердженню людини як найвищої соціальної цінності.
Особливе місце в цьому процесі займає дидактична культура викладача вищого навчального закладу як важлива складова його професійно-педагогічної культури, що дозволяе йому ефективно здійснювати професійну діяльність у нових організаційно-педагогічних 
умовах. Все це обумовлює необхідність вивчення та розробки проблеми підвищення готовності викладача до забезпечення сучасного освітнього процесу у вищому навчальному закладі, що відповідав би вимогам сучасності.

Для здійснення вільного, варіативного, повністю задовольняючі соціальні потреби навчання необхідний викладач, що володіє сучасним педагогічним мисленням, дидактичними ціннісними орієнтаціями, потребою у здійсненні повноцінної професійно-педагогічної діяльності, інноваційними технологіями навчання та формами взаємодії, які створювали б можливості для особистісної і професійної самореалізації студентів як майбутніх фахівців. Іншими словами, мова йде про виділення дидактичної культури викладача вищого навчального закладу в якості інтегруючої складової його професійної культури, що обумовлено рядом обставин:

1. Підвищенням в сучасних умовах вимог до рівня професіоналізму викладачів вищих навчальних закладів (ВН3), їх загальної та професійної культури.

2. Необхідністю системного формування дидактичної культури з урахуванням реалізації освітніх потреб особистості педагога.

Такий підхід обумовлює необхідність всебічного наукового аналізу проблеми формування дидактичної культури викладача навчального закладу.

Теоретичне осмислення особливостей цього процесу, розробка його моделі з виділенням педагогічних умов будуть сприяти підвищенню ефективності дидактичної діяльності викладача BH3.

Аналіз останніх досліджень і публікацій. Як свідчить аналіз літератури, проблема формування дидактичної культури викладача ВНЗ в сучасній педагогічній науці не була предметом спеціального дослідження. Разом 3 тим значна увага приділяється професійно-педагогічній культурі викладачів.

Формування різних сторін загальнопедагогічної культури, удосконалення професійної та педагогічної підготовки представлено в дослідженні окремих ii видів - методологічної (Е.В. Бережнова, В.В. Гура, А.І. Левко, В.А. Сластьонін, А.Н. Ходусов), філософської (А.А. Петров, Н.В. Піранашвілі), гуманітарної (Ю.В. Сенько, Н.Г. Сікорська, Е.Н. Шиянов), дослідницької(А.І.Кочетов, Е.М. Мурах,Я.В.Скалкова), комунікативної (В.С. Грехнев, В.А. Кан-Калик, А.В. Мудрик, В.В. Соколов), психологічної (Н.І. Ісаєва, А.К. Маркова, Л.М. Мітіна, Ф.Ш. Мухометзянова, Е.Д. Телєгіна), дидактичної
(Н.М. Фатьянова), дослідницької й технологічної (В.I. Максакова).

Базовими для розробки теорії дидактичної культури є дослідження сучасної дидактики, що отримали значний розвиток упрацях М.А. Данилова, В.К. Дьяченко, М.Н. Скаткіна, Б.П. Єсипова, В.І. Загвязинського, Г.А. Ільїна, В.І. Лозової, П.І. Підкасистого, Г.І. Щукіна і ін.

Питання інноваційної діяльності викладача розглянугі в роботах К. Ангеловського,Н.В. Горбунової, М.В. Кларіна, В.Я. Ляудис, Л.С. В.А. Сластьоніна, Л.А. Струценко, Л.Н. Шилової, Л.В. Ушеніной, О.Г. Хомерики, Н.Р. Юсуфбеков і ін.

Аналіз робіт названих авторів і ряду досліджень з вивчення особливостей сучасної освіти дозволяє зробити висновок про багатоаспектність та різноплановість розробки досліджуваної нами проблеми.

Формулювання цілей статті. Метою даної публікації є теоретичне обгрунтування сутності, змісту та структури поняття “дидактична культура викладача ВНЗ"; визначення критеріїв та показників сформованості дидактичної культури викладача вищого навчального закладу; розробка та часткова апробація моделі формування дидактичної культури викладача вищого навчального закладу.

Виклад основного матеріалу. Зміна ситуації в сфері освіти, перехід до нової освітньої політики, поліфункціональність змісту освіти, поява різних типів освітніх установ вимагають якісно нового підходу і до проблеми формування дидактичної культури викладача вищого навчального закладу.

Дослідження науково-педагогічної літератури показало, що, на відміну від педагогічної культури, феномен дидактичної культури викладача вищого навчального закладу практично не вивчений.

Як наукове поняття термін “дидактична культура" вперше був введений І.Ф. Ісаєвим [3; 4] і закріплений Н.М. Фатьяновою як вид професійно-педагогічної культури вчителя багатопрофільної гімназії [8].

Під дидактичнукультурою педагогаН.М. Фатьянова розуміє інтегральну якість особистості, що представлена єдністю мотиваційно-ціннісного, інноваційно-технологічного, індивідуальнотворчого компонентів, що забезпечують продуктивну дидактичну діяльність і творчу самореалізацію педагога [8].

Це визначення цілком є прийнятним до застосування в умовах загальноосвітнього навчального закладу, тому що виділяє два основних моменти - продуктивність професійної діяльності та самореалізацію самого вчителя. 
На думку Т.М. Боголіб, дидактична культура викладача вищого навчального закладу повинна характеризуватися необхідністю реалізації культурної складової професійної діяльності майбутнього фахівця, тому що основне завдання викладача вищої школи формування професіонала, що володіє певним рівнем професійної культури [1].

Рішення цього завдання вимагає іншого підходу як до рівня діяльності самого викладача, так і до організації дидактичного процесу.

У цьому, на нашу думку, складається специфіка виділеної нами проблеми дослідження.

Як свідчить аналіз психологопедагогічної літератури, проблема формування дидактичної культура викладача вищого навчального закладу, не була предметом комплексного спеціального наукового дослідження.

Виділення цієї проблеми в якості самостійної визначається специфічними рисами вищого (непедагогічного) навчального закладу:

a) значна частина викладачів, будучи фахівцями в певній сфері, немають спеціальної педагогічної підготовки;

б) у зв'язку з попередньої обставиною існує певний перекіс щодо “наповнення” студентів виключно професійними знаннями. При цьому досить часто ігноруються педагогічно ефективні методи реалізації завдань професійної освіти, головним 3 яких виступає формування культури професійної діяльності;

в) досвід дидактичної діяльності викладачів формується, в основному хаотично, безсистемно [6].

Щоб визначити місце дидактичної культури в системі педагогічної культури, нам представляється доцільним у рамках нашого дослідження підвести iii під інше, більше широке поняття. Таким родовим поняттям, на нашу думку, повинна виступати професійно-педагогічна культура. При цьому структура дидактичної культури є похідною від структури професійно-педагогічної культури і пов'язана 3 нею як часткове із загальним.

У своєму дослідженні ми дотримуємося підходу І.Ф. Ісаєва та Н.Л. Шеховської [4; 9] і відносимо дидактичну культуру до соціорегулятивної підсистеми професійно-педагогічної культури
(Рис.1). Носієм, суб’єктом дидактичної культури в нашому дослідженні виступає викладач вищого навчального закладу, який здійснює процес навчання в інноваційному режимі, що відповідає цілям і завданням сучасного навчального закладу. 
теоретичного підходу І.Ф. Ісаєва ми виділяємо наступні структурні компоненти [3].

1. Мотиваційно-ціннісний (система педагогічних цінностей, орієнтацій і переконань, включених у цілісний педагогічний процес; гуманістична особистісна позиція; мотивація на інноваційнодидактичну діяльність; сучасне педагогічне мислення)

2. Інноваційно-технологічний (професійна компетентність, способи і методи професійної діяльності; індивідуальний стиль професійної діяльності);

3. Індивідуально-творчий - розкриває креативні механізми оволодіння дидактичною культурою і їі втілення в діяльності як творчого акту.

У вивченні змістовних аспектів дидактичної культури особливий інтерес представляють виявлення та дослідження критеріїв і рівнів іiі сформованості.

У нашому дослідженні ми виходимо із сугності змісту та рівнів сформованості феномена дидактичної культури, найбільш всебічно й аргументовано поданих І.Ф. Ісаєвим [3].

Розроблена І.Ф. Ісаєвим система критеріїв оцінки рівнів сформованості професійнопедагогічної культури викладача вищої школи структурована за наступними параметрами:

1) ціннісне відношення до педагогічної реальності;

2) технолого-педагогічна готовність;

3) творча активність особистості викладача;

4) інтегративність видів педагогічної культури;

5) ступінь розвитку педагогічного мислення;

6) прагнення до професійно-педагогічному вдосконалюванню [3].

Дані параметри покладені в основу вироблених нами критеріїв сформованості дидактичної культури викладача вищого навчального закладу:

1) технологічна готовність;

2) готовність до здійснення інноваційної дидактичної діяльності;

3) інноваційна спрямованість дидактичної діяльності;

4) ступінь розвитку педагогічного мислення;

5) прагнення до професійно-педагогічного самовдосконалення;

6) ступінь творчої самореалізації.

Показники, що розкривають дані критерії, наведені в табл. 1.

На основі аналізу психолого-педагогічної літератури нами були визначені 4 рівні сформованості дидактичної культури: адаптивний, репродуктивний, евристичний, креативний.
Адаптивний рівень характеризується знанням дисципліни, що викладається, основ педагогічних і психологічних наук, однак система знань і готовність до їх використанню в необхідних педагогічних ситуаціях відсутні, а мета і завдання власної педагогічної діяльності визначені в загальному вигляді. Професійно-педагогічна діяльність будується за алгоритмом, творчість практично не проявляється.

Репродуктивний рівень відрізняється проявом тенденції до стійкого ціннісного ставлення до педагогічної діяльності, більш високо оцінюється роль психолого-педагогічних знань, проявляється прагнення до установлення суб'єкт-суб'єктних відносин між учасниками педагогічного процесу, відзначається більш високий ступінь задоволеності власною педагогічною діяльністю. Творча активність проявляється в рамках відтворюючої діяльності, але 3 елементами пошуку нових рішень у стандартних педагогічних ситуаціях.

Евристичний рівень характеризується стійкістю та усвідомленістю шляхів і способів професійної діяльності. Високий рівень комунікативної та евристичної культури дозволяє впроваджувати активні методи навчання, проблемні форми організації навчального процесу. Власна діяльність відрізняється постійним пошуком, впровадженням нових технологій навчання й виховання, готовністю передавати свій досвід іншим.

Креативний рівень відрізняється високим ступенем результативності педагогічної діяльності, мобільністю психолого-педагогічних знань. У діяльності викладача важливе місце займають педагогічна імпровізація, педагогічна інтуїція, що забезпечують продуктивне вирішення педагогічних завдань. У структурі особистості поєднані наукові та педагогічні інтереси. Викладач зацікавлено та цілеспрямовано підвищує свою педагогічну майстерність, рівень дидактичної культури, охоче ділиться особистим педагогічним досвідом і вивчає досвід інших.

Таким чином, системне, цілісне подання дидактичної культури, виділення її сутнісних рис і функцій, обгрунтування критеріїв і рівнів іiї сформованості $\epsilon$ теоретичною передумовою для дослідження тенденцій і умов формування досліджуваного феномена.

Методом теоретичного осмислення проблеми формування та розвитку дидактичної культури викладача вищого навчального закладу в нашому дослідженні $\epsilon$ моделювання, що $є$ універсальним способом пізнання дійсності та широко поширене в педагогічній науці. Алгоритм побудови 
Критерії та показники сформованості дидактичної культури викладача вищого навчального закладу

\begin{tabular}{|c|c|}
\hline Критерії & Показники \\
\hline 1 & 2 \\
\hline 1. Технологічна готовність & $\begin{array}{l}\text { 1) сформованість дидактичних цінностей, ціннісного } \\
\text { відношення до дидактичної діяльності; } \\
\text { 2) ступінь технологічної готовності } \\
\text { до здійснення дидактичної діяльності в системі вищої } \\
\text { освіти; } \\
\text { 3) сформованість уміння вирішувати } \\
\text { дидактичні задачі в межах традиційного } \\
\text { навчання }\end{array}$ \\
\hline 2. Інноваційна готовність & $\begin{array}{l}\text { 1) ступінь теоретичної та методологічної готовності до } \\
\text { здійснення інноваційно-дидактичного процесу; } \\
\text { 2) ступінь готовності до дидактичної } \\
\text { культуротворчості; } \\
\text { 3) сформованість уміння вирішувати дидактичні задачі в } \\
\text { умовах інноваційно-дидактичного середовища }\end{array}$ \\
\hline 3. Інноваційна спрямованість навчання & $\begin{array}{l}\text { 1) постійне практичне використання в дидактичній } \\
\text { діяльності авторських та } \\
\text { привнесених із досвіду колег інновацій; } \\
\text { 2) здатність до формування власних } \\
\text { інноваційних елементів дидактичного процесу; } \\
\text { 3) ступінь освоєння інноваційних прийомів і методів у } \\
\text { практичній діяльності }\end{array}$ \\
\hline $\begin{array}{l}\text { 4. Ступінь розвитку педагогічного } \\
\text { мислення }\end{array}$ & $\begin{array}{l}\text { 1) рівень теоретичного і практичного осмислення власної } \\
\text { дидактичної діяльності; 2) розвинена рефлексивна культура; } \\
\text { 3) рівень проблемності мислення }\end{array}$ \\
\hline $\begin{array}{l}\text { 5. Прагнення до професійно-педагогічної } \\
\text { досконалості і творчості у професійній } \\
\text { діяльності }\end{array}$ & $\begin{array}{l}\text { 1) наявність власної дидактичної системи; } \\
\text { 2) готовність до взаємної зі студентами дидактичної } \\
\text { творчості; } \\
\text { 3) продуктивність дидактичної діяльності }\end{array}$ \\
\hline
\end{tabular}

запропонованої моделі може бути представлений у такий спосіб.

1. Уточнення компонентного складу, структури та організації складових частин моделі, виявлення провідних взаємодій між ними. Структура моделімістить у собі 3 структуроутворюючих компонента - мотиваційно-ціннісний, інновавційнотехнологічний i індивідуально-творчий; 3 функціональних модулі - загальнодидактичний, предметно-методичний іпсихолого-дидактичний; 9 взаємозалежних і взаємообумовлених блоків, які наочно представлені на Рис. 2.

2. Виявлення зовнішніх зв'язків моделі, виділення головних 3 них. У ході аналізу структури запропонованої моделі в якості основних ii зовнішніх зв'язків ми виділили взаємозв'язок із предметно-методичною та психолого-педагогічною підготовкою викладача.

3. Визначення функцій моделі. Основними функціями запропонованої моделі в нашому розумінні виступають іiї пізнавальна (гностична) і формуюча функції.
4. Вивчення динаміки моделі, виявлення основних закономірностей і тенденцій їі розвитку.

Дослідники виділяють упроцесі професійного становлення педагога три періоди: 1) допрофесійний, довузівський, пов'язаний з вибором професії; 2) початковий, вузівський період, під час якого формуються основи професійно важливих умінь і властивостей особистості педагога; 3) основний, професійний період розвитку “всіх сутнісних сил” особистості вчителя 3 метою її найбільш повної самореалізації в педагогічній діяльності $[2 ; 5 ; 7]$.

У змістовному відношенні процес формування дидактичної культури, на нашу думку, повинен складатися, 39 функціональних блоків, що містять інформацію, орієнтовану на формування певної групи професійно та особистісно значущих якостей відповідно до запропонованої моделі (Рис. 2.).

Блок I. Системне бачення педагогічної реальності: теоретичні знання з основ системного аналізу, спеціальна робота з освоєнню зовнішньої та внутрішньої структури професійної діяльності 


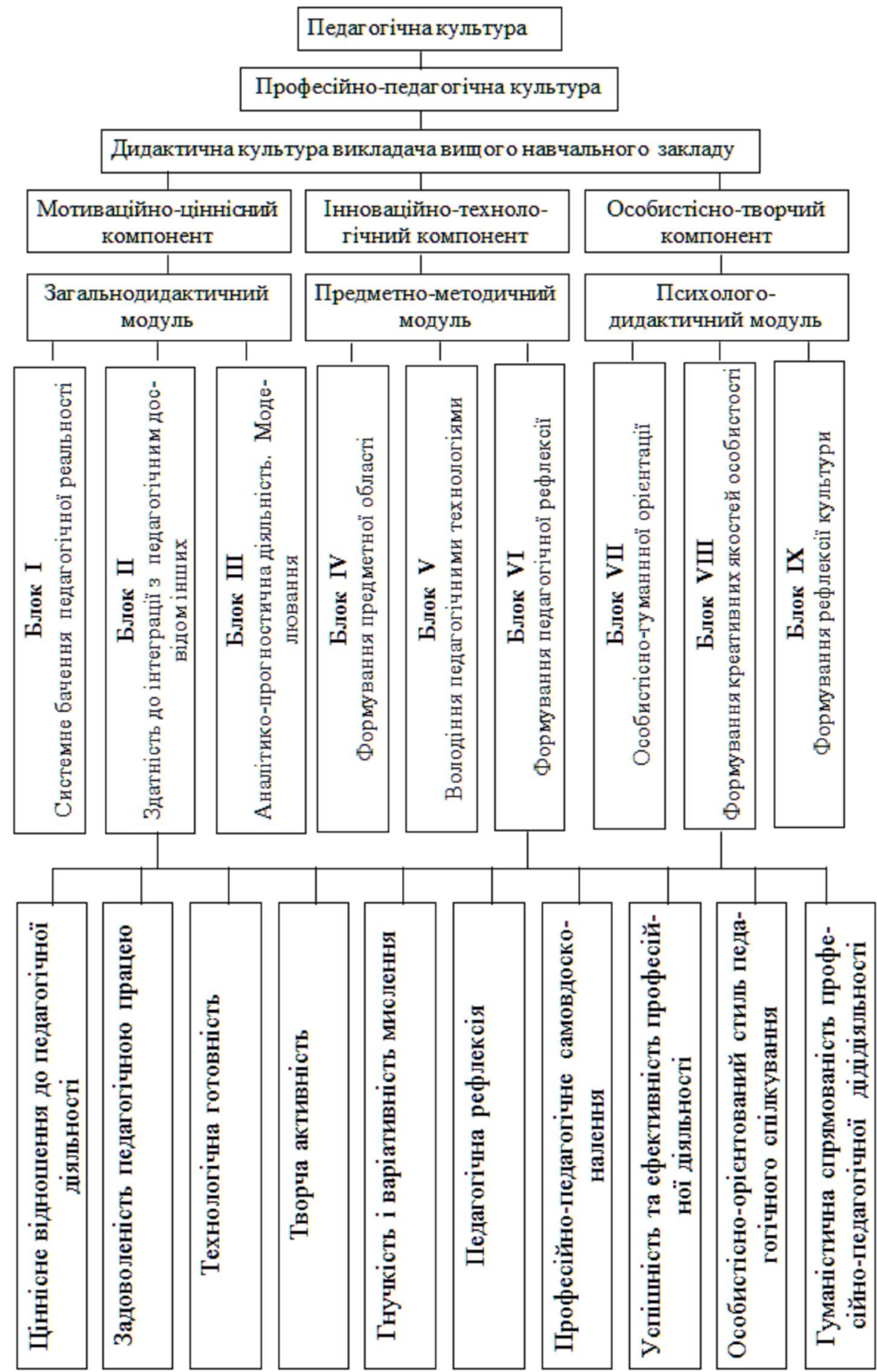

Рис. 2. Модель формування дидактичної культури викладача ВНЗ

педагога; теоретичні знання 3 основ моделювання; практична робота 3 моделюванню педагогічних систем та процесів; формування вмінь прогнозування результатів власної діяльності і її наслідків.

Блок II. Здатність до інтеграції з педагогічним досвідом інших: практичне освоєння досвіду, організація різних акцій, що сприяють взаємодії педагогічного досвіду (спільні дослідження, спільне навчання, спільна розробка та реалізація різних проектів).

Блок III. Аналітико-прогностична діяльність, моделювання: формування вмінь аналізу, синтезу та узагальнення педагогічних явищ і процесів; 
формування навичок педагогічного передбачення як основи прогнозування; освоєння критеріїв адекватності аналітико-прогностичної діяльності цілям і завданням освітньої установи та власної професійної діяльності.

Основні методи - групові тренінги, рольові та організаційно-діяльнісні ігри, “мозковий штурм”, ігрове моделювання, виконання творчопошукових завдань.

Блок IV. Формування предметної області: формування вмінь діяти в рамках дисципліни, що викладається; формування навичок відбору, обробки, зберігання, інтерпретації та організації навчальної інформації.

Основні методи - індивідуальна робота 3 конструювання та освоєння нового предметного змісту та критеріїв його відбору, колективна діяльність 3 їх теоретичної апробації (семінари, конференціі).

Блок V. Володіння педагогічними технологіями: формування ключових понять: Освоєння педагогічних технологій здійснюється у двох основних напрямках: спеціальна діяльність у формах ігрового моделювання (власне сам навчальний процес) і практична діяльність щодо використання отриманих знань і вмінь.

Блок VI. Формування педагогічної рефлексії. Основні форми - тренінгові заняття рефлексивного аналізу власної педагогічної діяльності та діяльності інших, оформлення їх у вигляді узагальнених матеріалів, моделювання, розробка алгоритмів, взаємонавчання, практична діяльність щодо використанню отриманих знань і вмінь.

Блок VII. Формування індивідуальногуманістичної орієнтації: формування комунікативної культури в широкому значенні; виявлення протиріч між тенденцією до гуманізації людських відносин і реальною позицією педагога у вітчизняній педагогічній традиції; формулювання понять діалогу, складної комунікації, компромісу; проведення спеціальної (теоретичної та практичної) роботи щодо зняття стереотипів професійного мислення та поведінки педагогів.

Основні методи - широке використання ігрового моделювання, спеціальні синтетичні курси, що включають лекції, самостійну індивідуальну роботу, семінари з використанням ігротехнічних засобів.

Блок VIII. Формування креативних якостей особистості педагога: а) організація практичної діяльності щодо формування та розвитку, здатності до самозміни (самодіагностики); б) здатності до створення (проектування) принципово нових систем у сфері професійної діяльності; в) здатності до професійного самовизначення, прийняття повної відповідальності за результати своєї професійної діяльності; г) здатності до отримання інноваційного результату в професійній діяльності; д) здатності до подолання традиційного погляду на педагогічний експеримент як на природничо-наукову процедуру, успішність якої жорстко детермінована прогнозованими результатами.

Основні способи діяльності - ігрове моделювання процесу проектування педагогічного експерименту, практична експериментальна діяльність, наукова праця по оформленню та аналізу результатів експериментальної діяльності, соціальнопсихологічні тренінги 3 професійного та особистісного самовизначення.

Блок IX. Формування рефлексивної культури: курс з теорії рефлексивного мислення; придбання навичок саморефлексії та умінь організатора спільних рефлексивних процесів в рамках професійної діяльності; формування розуміння цінності та необхідності рефлексивної діяльності педагога, показ практичної значимості саморефлексії і спільної рефлексії в повсякденній педагогічній роботі.

Основні методи та форми: тренінги соціальнопсихологічного і методологічного характеру щодо освоєнню засобів рефлексивної діяльності.

Реалізація даної моделі можлива в рамках певних технологій, які будуть сприяти формуванню діяльнісної основи цього процесу, забезпечать перенос знань у сферу праці, будуть впливати на цілеспрямованість та життєву стратегію викладача.

За підсумками формувального експерименту, проведеного на базі вищих навчальних закладів міста Харкова (ХНМУ, ХМОПО та ін.), впровадження запропонованої нами моделі формування дидактичної культури викладача вищого навчального закладу дало можливість отримати позитивну динаміку рівнів сформованості дидактичної культури викладачів ВН3: за даними експертної оцінки скоротилася кількість викладачів за першими двома рівнями сформованості дидактичної культури: адаптивному - $324,1 \%$ до $13,9 \%$, репродуктивному - з 31,5\% до $30,9 \%$. Спостерігається зростання числа викладачів, що освоїли евристичний рівень ( $36,5 \%$ до 45,4\%) і креативний рівень (з 7,9\% до 10,1\%).

Таким чином, результати експериментальної роботи підтвердили робочу гіпотезу дослідження і сприяли вирішенню всіх завдань дослідження.

Висновки та перспективи подальших 
досліджень. Найбільш істотні результати проведеного дослідження полягають в наступному:

а) проведені теоретичне дослідження та подано визначення дидактичної культури викладача як суспільно-педагогічного феномена і важливої складової професійно-педагогічної культури, досліджені їі генезис, процес формування та розвитку;

б) обгрунтована система критеріїв і показників дидактичної культури викладача вищого навчального закладу;

в) розроблена модель формування дидактичної культури викладача вищого навчального закладу, яка враховую основні тенденції сучасної парадигми освіти та специфіку навчального закладу;

г) експериментально підтверджена можливість інтерпретації дидактичної культури викладача вищого навчального закладу як одного з факторів успішності його професійної діяльності.

Як напрямки подальшого наукового пошуку ми виділяємо: дидактичне забезпечення самого процесу формування та розвитку дидактичної культури викладача вищого навчального закладу; аналіз дидактичних компонентів забезпечення ефективної професійної діяльності та кореляційних зв'язків між дидактичною культуротворчістю і формуванням професійної культури студента як майбутнього фахівця; культурологічний підхід у дослідженні дидактичної діяльності та механізмів дидактичної творчості.

\section{ЛІТЕРАТУРА}

1. Боголіб Т.М.Принципии управліннявузом/ Т.М. Боголіб. - Переяслав-Хмельницький: Б.в., 2004. - 202 с.

2. Вища освіта в Україні: Навч. посібник/ В. Г. Кремень [та інші]; ред. В. Г. Кремень, С. М. Ніколаєнко. - К.: Знання, 2005. - 327 с.

3. Исаев И.Ф. Теория и практика формирования профессионально-педагогической культуры преподавателя высшей школы. - М. - Белгород, 1993. - 219 с.

4. Исаев И.Ф., Шеховская Н.Л. Колледж как инновационное образовательное учреждение /Опыт исследования профессионально-педагогической культуры. Монография. - Белгород, 1997. - 144 с.

5. Крижко В.В. Антологія аксіологічної парадигми управління освітою: Підручник для пед. ун-тів/ В. В. Крижко. - К.: Освіта України, 2005. - 440 с.
6. Лекції з педагогіки вищої школи: Навч. посібник/ В. І. Лозова [та ін.]. - Х.: ОВС, 2006. - 496 с.

7. Проектний підхід до управління навчальним закладом: Навчально-методичний посібник/ О. І. Мармаза. - Х.: Основа, 2003. - 80 с.

8. Фатьянова Н.М. Формирование дидактической культуры учителя многопрофильной гимназии: Дисс. ... канд. пед. наук. - Белгород, 1999. - 274 с.

9. Шеховская Н.Л. Формирование профессиональнопедагогической культуры преподавателей колледжа: Дисс. ... канд. пед. наук. - Белгород, 1997. - 197 с.

\section{REFERENCES}

1. Boholib, T. M. (2004). Pryntsypy upravlinnia vuzom [Principles of university management]. Pereiaslav-Khmelnytskyi: Pereiaslav-Khmelnytskyi State University, 202 p. [in Ukrainian].

2. Kremen, V. H. \& Nikolaienko, S. M. (Eds). (2005). Vyshcha osvita $v$ Ukraini [Higher education in Ukraine]. Kyiv: Znannia, 327p. [in Ukrainian].

3. Isaev, I. F. (1993). Teoriya i praktika formirovaniya professionalno-pedagogicheskoy kultury prepodavatelya vysshey shkoly [Theory and practice of the formation of professional and pedagogical culture of a teacher of higher education]. Moscow: Belgorod, 219 p. [in Russian]

4. Isaev, I. F. \& Shekhovskaya, N. L. (1997). Kolledzh kak innovatsionnoe obrazovatelnoe uchrezhdenie. Opyt issledovaniya professionalno-pedagogicheskoy kultury [College as an innovative educational institution. Experience in the study of professional and pedagogical culture]. Belgorod, 144 p. [in Russian].

5. Kryzhko, V. V. (2005). Antolohiia aksiolohichnoi paradyhmy upravlinnia osvitoiu [Anthology of the axiological paradigm of education management]. Kyiv: Osvita Ukrainy, 440 p. [in Ukrainian].

6. Lozova, V. I. (2006). Lektsii z pedahohiky vyshchoi shkoly [Lectures of higher education pedagogy] Kharkiv: OVS, 496 p. [in Ukrainian].

7. Marmaza, O. I. (2003). Proektnyi pidkhid do upravlinnia navchalnym zakladom [Project approach to management of an educational institution]. Kharkiv: Osnova, 80 p. [in Ukrainian].

8. Fatyanova, N.M. (1999). Formirovanie didakticheskoy kultury uchitelya mnogoprofilnoy gimnazii [Formation of the didactic culture of the teacher of a multidisciplinary gymnasium]. Candidate's thesis.Belgorod: 274p. [in Russian].

9. Shekhovskaya, N.L (1997). Formirovanie professionalno-pedagogicheskoy kultury prepodavateley kolledzha [Formation of professional and pedagogical culture of college teachers]. Candidate's thesis. Belgorod: 197 p. [in Russian].

Стаття надійшла до редакції 10.04.2018

\section{G5808NC2G580

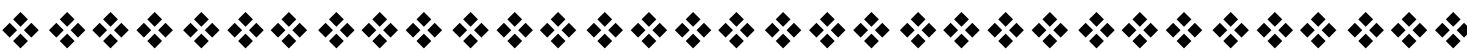

